This is an electronic reprint of the original article. This reprint may differ from the original in pagination and typographic detail.

Author(s): Hakala, Ismo; Härmänmaa, Tuomo; Laine, Sanna; Myllymäki, Mikko

Title: $\quad$ How Do Students Blend Their Studies Based on Time and Place?

Year: $\quad 2017$

Version:

Please cite the original version:

Hakala, I., Härmänmaa, T., Laine, S., \& Myllymäki, M. (2017). How Do Students Blend Their Studies Based on Time and Place?. In L. G. Chova, A. L. Martínez, \& I. C. Torres (Eds.), EDULEARN17 Proceedings. 9th International Conference on Education and New Learning Technologies (pp. 2481-2489). IATED Academy. EDULEARN

Proceedings. https://doi.org/10.21125/edulearn.2017.1520

All material supplied via JYX is protected by copyright and other intellectual property rights, and duplication or sale of all or part of any of the repository collections is not permitted, except that material may be duplicated by you for your research use or educational purposes in electronic or print form. You must obtain permission for any other use. Electronic or print copies may not be offered, whether for sale or otherwise to anyone who is not an authorised user. 


\title{
HOW DO STUDENTS BLEND THEIR STUDIES BASED ON TIME AND PLACE?
}

\author{
Hakala Ismo, Härmänmaa Tuomo, Laine Sanna, Myllymäki Mikko \\ University of Jyväskylä (FINLAND)
}

\begin{abstract}
The flexibility of participating in education can be improved by utilising lecture videos. By producing videos of contact teaching lectures and offering them to students as real-time videos and recordings, opens up new participation opportunities regarding time and place. This study examines an environment in which students can freely choose their mode of participation for each individual lecture. The objective has been to identify possible changes in participation by looking at participations between 2008-2012 and in 2017. According to the results, teaching bound to a specific location has disappeared almost entirely. Participation in teaching is instead mostly done using videos. Students participate in teaching using live or on-demand videos, or by blending these two methods. This means that plenty of students in the degree programme blend their studies particularly regarding time.
\end{abstract}

Keywords: time-based blended learning, video lecture, blended learning, participation.

\section{INTRODUCTION}

The popularity of videos among publishing formats has grown rapidly at the same time as the time spent watching traditional TV has decreased. Videos are used in online news, education, marketing, social media, etc. Another trend is that the proportion of video consumed on mobile devices is increasing. As videos are now a part of everyday life, they are also naturally utilised in higher education.

Lecture videos provide a flexible way to participate in teaching. With the help of videos, educational organisations are able to diversify teaching and serve a wider and more heterogeneous group of students. Real time videos enable independence from place, while on-demand videos offer independence from place and time.

Videos can also be utilised in constructing an educational programme following the blended learning model. Although there are multiple definitions for the blended learning concept, the most common and classic approach is to define blended learning as education that combines online digital media with traditional, instructor-led classroom methods. Norberg et al. [1] floated an idea of a "time-based blended learning model". This model comprises of synchronous and asynchronous learning elements. Synchronous learning may include, e.g. face-to-face teaching, video conferencing, chat functions, and real time videos. Asynchronous elements include books, assignments, discussion forums, on-demand videos, etc. According to this definition, neither traditional classroom teaching nor the physical presence of a lecturer or student is required. Time-based blended learning can take place entirely online.

Recording of lectures is an efficient way to implement blended learning based on place or time, since it does not require any additional effort from the lecturer. The lecture video production has been a crucial factor in our master's degree education in mathematical information technology directed at adult students. Over the years, the production process has made great progress. The video capturing is automated, and the lecture videos are distributed through a virtual campus environment, which includes tools that enable interactivity. For every lecture, the students can choose whether to attend face-to-face teaching or watch the lecture video either in real time or as on-demand video.

This paper examines how students blend their studies based on location and time in an environment where they have an opportunity to choose the most suitable alternative for participating in a lecture. Lecture participations can be carried out as face-to-face teaching, or by using live or on-demand videos. By mixing these three participation methods, students can blend their studies to correspond with the classic blended learning model or time-based blended learning.

We wanted to explore how the proportions of these participation modes have changed over the years in our educational context. The statistics have been collected from server log files and face-to-face participation data. 


\section{BLENDED LEARNING}

During the past ten years, blended learning has spread rapidly, which can be seen in the amount of studies conducted on the topic [2], [3], [1]. The growth of blended learning has been explained with e.g. its ability to utilise educational potential to the maximum, which is achieved by mixing traditional academic approaches with internet-based tools and services [1]. The method's growth especially in higher education has been affected by research results, according to which blended learning solutions lead to better course performance, lower course drop-out rates and better student satisfaction [1]. Students also seem to gravitate towards a blended model when given a choice of studying methods [1], [4]. Teaching staff has likewise been noted to be more satisfied with blended learning courses than traditional ones [5].

There have been many suggested definitions for the term blended learning (e.g. [6], [2], [7]). The definition is usually based on what is being blended [8], [9]. Even though there are multiple explanations for the term, according to one almost classic definition, blended learning is considered a combination of contact and distance teaching [10], [6]. Blended education is seen to combine the best elements of both methods. This type of approach improves the flexibility of education while maintaining the personal contact of traditional classroom teaching [1]. In other words, this classic definition sees blending determined by at least location. In practice, this also means that education utilising the environments and interaction tools of information and communications technologies is realised alongside traditional classroom teaching. The relationship between contact teaching and online education can vary a lot. Numerous definitions have been suggested for the relationship [11], [12], [13], [14]. There have been various definitions regarding what to call education where a portion of the teaching is organised online (e.g. [12], [15]).

In other words, according to classic definition, blended learning combines activities bound to a location, such as traditional contact teaching, with activities independent of this. The classic definition of blended learning does not differentiate between whether online activities that are independent of location are realised synchronously or asynchronously. In synchronous teaching, students participate in education simultaneously with the teaching session, while in asynchronous teaching students can study when it best suits them. According to the classic definition, the elements that are primarily blended are contact teaching and online learning. However, in modern virtual environments, education is no longer necessarily realised as contact teaching. Does this mean that blended learning cannot be implemented in such environments?

During the last ten years, studies have also discussed blending that focuses on the time of studying. Power [16] has introduced the concept of so-called "blended online learning". In this model, contact teaching is replaced weekly with e.g. video conferences. Furthermore, studying is done completely independently in online environments between these synchronised learning situations. In other words, all studying is done independent of place, but occasionally temporally synchronised. The education is realised entirely online, while still featuring elements of blending. Norberg et al. [1] present a similar solution, the time-based blended learning model, which also focuses on the temporal aspect. The timebased blended education combines various asynchronous and synchronous activities.

Synchronous teaching can be realised as e.g. contact teaching, live videos or in chat rooms. The implementation can be technologically assisted and also either dependent or independent of location. The key feature is that synchronous teaching enables the utilisation of real-time interaction in teaching. A downside of synchronous teaching is the lack of temporal flexibility, as well as challenging technical production requirements [17]. The continuous development of technology, especially in the field of communications, enables more natural online interaction, and through this, better implementation of synchronous teaching that is independent of location. In asynchronous teaching, the teaching and studying take place during different times. Asynchronous teaching can also be realised traditionally without technological tools (with e.g. books and learning tasks), but also with them (e.g. on-demand videos). Realising interaction is naturally more challenging with asynchronous education. There are, however, multiple solutions for this within the selection of tools offered by Learning Management Systems (LMS), for instance.

In an article of theirs, Norberg et al. [1] point out that especially courses on which lectures are recorded and offered to students later are efficient in regard to blended learning. They enable both synchronous participation by attending lectures or watching live videos, as well as asynchronous participation by watching lecture recordings. In addition, studies can be arranged to utilise a combination of all of these methods. On courses like this, blending can be done in regard to both time and place. 
Students' asynchronous work can nowadays be very efficiently supported with the use of LMS and social media applications, for instance [1]. Previously, students themselves were primarily responsible for their own asynchronous studies. Time-based blending also enables the realisation of entirely new pedagogical solutions [1]. Since both synchronous and asynchronous studying can be based on the use of technologies, traditional elements of teaching can also be made to switch places. This allows for the implementation of e.g. flipped learning, in which traditionally lecture-heavy activities are arranged as self-studies, while face-to-face classes are used for cooperative studying. Time-based blending offers clear benefits from the students' point of view. Environments where students have access to course contents regardless of time and place allow them to use their resources more efficiently [1]. With suitable technological solutions, students can be given an opportunity to decide the degree of blending in their own studies in regard to time and place.

\section{RESEARCH ENVIRONMENT}

This study examines the master's degree programme in mathematical information technology at Kokkola University Consortium Chydenius. All students in the degree programme are working adults with families. Most notable challenges for these types of students are those regarding scheduling, which they must balance between work, family and studying. In practice, this means that due to time constraints, the students have limited opportunities to participate in traditional contact teaching. Because of this, the degree programme has for a long time been under development in order to incorporate educational technologies.

All teaching in the degree programme is organised as traditional contact teaching, in addition to which all classroom situations are recorded and made available online as live and on-demand videos. Continuing to organise contact teaching also retains the option for those students who would rather attend classes and who are able to do so.

Students have multiple options for participating in individual lectures. They do not have to decide their participation method in advance, and can instead choose the most suitable one for each lecture. These include traditional contact teaching, live videos and on-demand videos. Students can blend their studies by combining these methods between lectures. In other words, students are in control of the degree of blending in their own studies. Examining the blending occurring here in regard to the aforementioned definitions of blended learning, students can blend their studies location-wise by attending contact teaching for some lectures and watching live or on-demand videos of others. On the other hand, studies can also be blended time-based by participating synchronously by utilising contact teaching or live videos, as well as by participating asynchronously using on-demand videos. Worth noting is that if they so desire, students can also study without any blending by exclusively attending contact teaching or using live or on-demand videos for distance learning. All possible forms of participation are presented in Fig. 1.

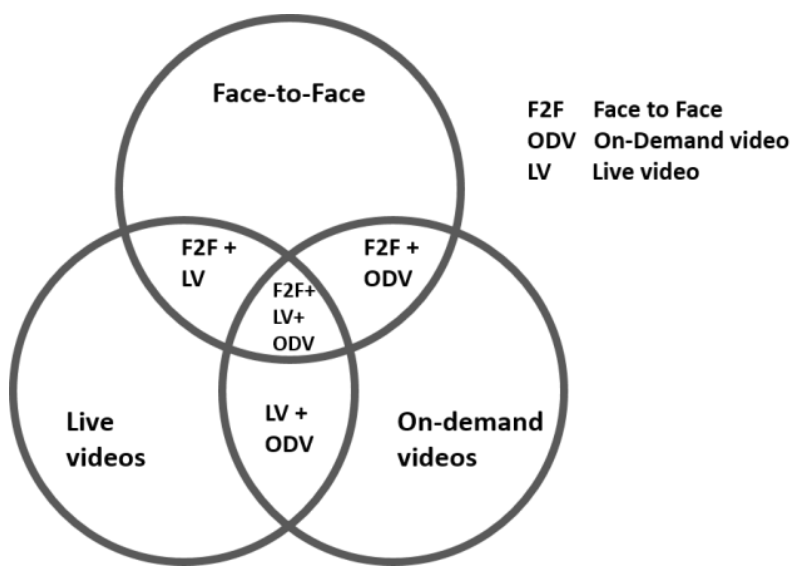

Figure 1. Available methods of participating in the IT master's degree programme.

In all of these participation methods, students also have access to possible written course materials. Furthermore, studying can be done using only the written materials, i.e. without videos or contact teaching. Students have access to the lecture videos throughout the course, meaning that videos can also be used for revision regardless of how one chooses to participate. 
To support participation using videos, a virtual learning environment suited for watching videos called CiNetCampus Studies was developed in order to improve students' interaction and collaboration opportunities. The virtual environment makes especially synchronous participation using live videos easier. In this environment, students can communicate with the lecturer and each other while watching lecture videos by using the integrated chat function. The environment also has a so-called lecturer's view module, which is projected to the wall of the classroom. This tool displays the questions asked through chat in the classroom, as well as who are participating in the education using video. A module that logs the attendance of contact teaching students correspondingly shows distance learners who are present in class. For highly interactive teaching situations, such as seminars and study guidance, the environment features an integrated video conferencing functionality, which enables two-way real-time communications and file sharing.

For years now, video participation has had a significant role in participating in the degree programme [18]. During the realisation of the education programme, it has been noted that participation in contact teaching has diminished up to the point of near non-existence over the years. The purpose of this study has been to examine the current state of participation and how participation in education has changed in an environment with multiple methods for doing so and the freedom to choose between them.

\section{RESULTS}

During 2008-2012, the lecture videos were streamed using Windows Media Server (WMS). The server provides log data that can be used to examine students' viewing habits. The log data indicates whether the video view is made live or as on-demand, and the time spent watching each lecture video. To supplement participation data, lecture attendances were collected manually on several courses starting from 2008. At the end of 2012, the media server was changed to Wowza Engine to serve more a heterogeneous group of playback clients and devices. After that, the CiNetCampus Studies environment, which included a specific participation data module, was launched. The participation data module produces the video utilisation data that is formatted to apply to our use. The lecture attendance data collection was also automated.

\subsection{Analysis of Lecture Participations}

Based on log and attendance data, students' lecture participations were classified as face-to-face, live video or on-demand video participations. The classification was defined so that a student could take part in a lecture using only one of these three ways. If a student had attended face-to-face teaching or watched a lecture as live video, these participation modes were considered as primary, and possible on-demand viewing later on that particular lecture video was considered as revision. If the on-demand video was a student's only medium, the lecture participation was classified as on-demand.

To examine the change in students' participation methods, we compared recent participation data to the data collected before the CiNetCampus environment was implemented. Participation data recorded during roughly the past five months using CiNetCampus' participation module included 440 lecture participations. Because of the changes made to CiNetCampus in late November 2016, the data was collected from the end of November 2016 (30.11.2016) to the beginning of May 2017 (8.5.2017). We refer to that data later on as "spring 2017 data". Some courses that included video-only lectures were omitted from the analysis. The comparative data was collected between 2008- 2012, at the WMS operation time, and it contained 3772 lecture participations. The courses on which manual face-to-face attendance data was not collected were left out of the analysis. The results are shown in Fig. 2.

Fig. 2 clearly shows that participation using on-demand videos remained steady, while participation using face-to-face teaching and live videos changed. While between 2008-2012 a fifth of all participations were conducted by using live videos and slightly under a third by attending face-to-face teaching, the corresponding portions in the spring 2017 data were slightly under half for live videos and only $2 \%$ for face-to-face teaching. Worth noting is also that the reduction in attending face-to-face teaching did not result in changes regarding participation occurring synchronously with the lectures. In both sets of data, nearly half of all participations occurred synchronously and slightly more than half asynchronously. 
2008-2012 data $(\mathrm{N}=3772)$

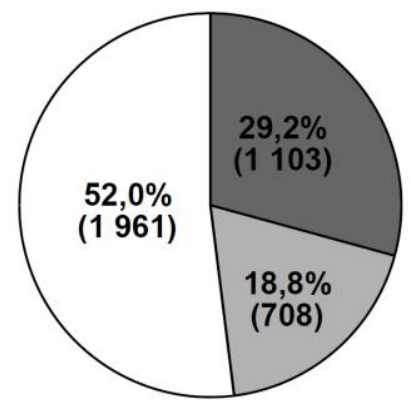

Spring 2017 data $(\mathrm{N}=\mathbf{4 3 0})$

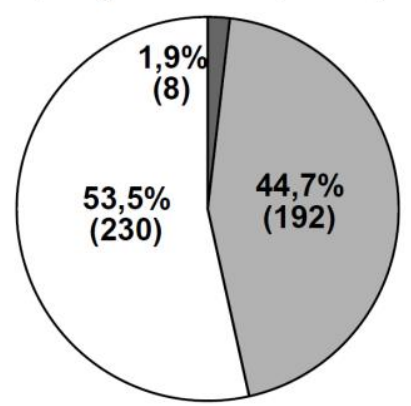

Participation method

$\square$ Face-to-face

$\square$ Live video

$\square$ On-demand video

Figure 2. Distribution of student participations between 2008-2012 and in spring 2017.

\subsection{Student-specific Analysis of Lecture Participations}

Besides lecture participations, participation in education can also be examined on the basis of individual students during a specific time period. In doing so, the focus is on how much a student has participated in education using on-demand videos, live videos and by attending face-to-face teaching. The results are presented as the proportional distribution of these methods.

The lecture participations in the 2008-2012 data included 92 students. On average, a student had participated in 41 lectures. In the spring 2017 data, there were 48 students and the average number of lecture participations was nine. Table 1 depicts the distribution of participation methods that an average student used in each group. The share of on-demand participation has remained same, while changes have taken place in the portions of face-to-face and live video participation. The results are similar to the above.

Table 1. The average distributions of participation methods.

\begin{tabular}{l|c|c|c}
\hline \hline & $\begin{array}{c}\text { Average share of } \\
\text { face-to-face } \\
\text { participation }\end{array}$ & $\begin{array}{c}\text { Average share of } \\
\text { live video } \\
\text { participation }\end{array}$ & $\begin{array}{c}\text { Average share of } \\
\text { on-demand } \\
\text { participation }\end{array}$ \\
\hline $\begin{array}{l}\text { Students in 2008-2012 } \\
\text { data, } \mathrm{N}=93\end{array}$ & $26,4 \%$ & $16,9 \%$ & $56,8 \%$ \\
\hline $\begin{array}{l}\text { Students in the spring 2017 } \\
\text { data, N=48 }\end{array}$ & $1,3 \%$ & $39,7 \%$ & $59,0 \%$ \\
\hline \hline
\end{tabular}

The above results do not take the portion of blended education into account at all. Examining studentspecific participation methods during a time period also allows one to examine how students combine various ways of participation (face-to-face teaching, live and recorded video) in their studies. Doing so provides information not only about contact teaching and live and recorded video, but also about different combinations of these methods. These are presented in Fig. 3. Based on their participations during a certain period of time, each student can be placed into one category. For instance, if a student has attended face-to-face teaching and watched live videos, said student would be placed in category $\mathrm{F} 2 \mathrm{~F}+\mathrm{LV}$. On the other hand, if the student is in e.g. category F2F, this means that all of his or her participations were face-to-face teaching. Fig. 3 presents the distribution of students into these categories in proportional shares between 2008-2012 and in 2017. 


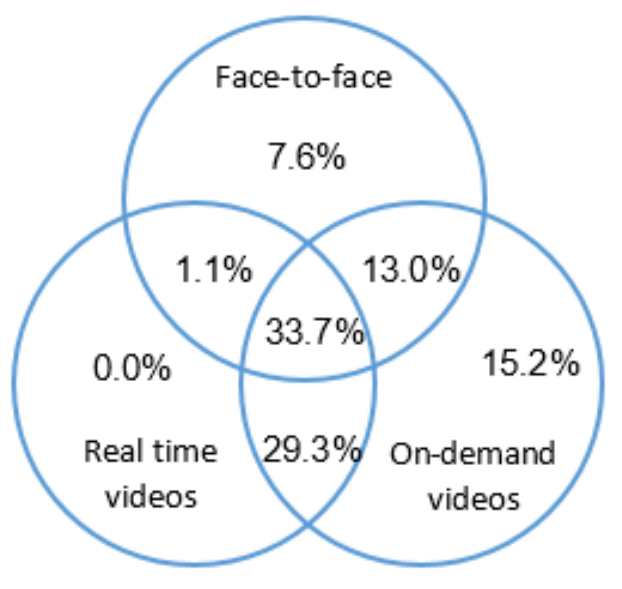

2008-2012

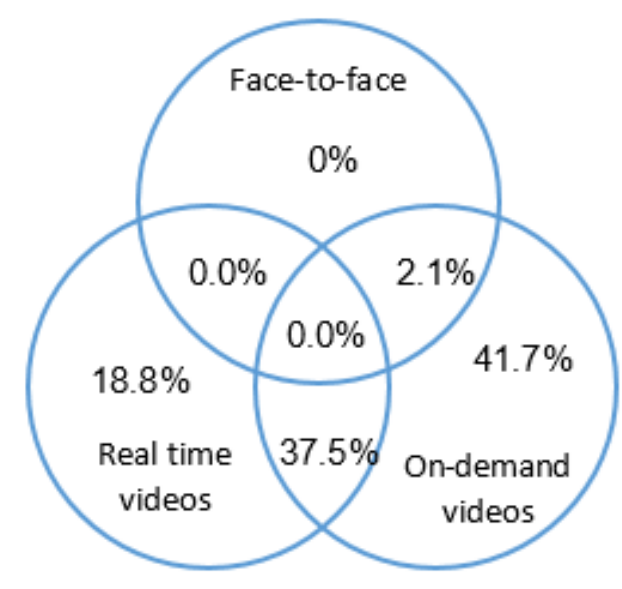

Spring 2017

Figure 3. Categorisation of students according to participation method.

Fig. 3 shows that the portions of pure face-to-face teaching, on-demand video and live video were fairly small between 2008-2012. Roughly a sixth of students used recordings and less than a tenth participated in contact teaching. There were no students who exclusively watched live videos, while in spring 2017 nearly a fifth of all students studied exclusively using this method. The portion of those who only studied using on-demand videos (2/5) was also significant. The role of face-to-face teaching has died out in its entirety.

Between 2008-2012, the significance of teaching bound to a location was significant, with slightly more than half of the students participating in such a manner. In other words, these students made use of face-to-face teaching, either by attending it exclusively or by blending it with live or on-demand videos. By far the most popular option was to utilise all three participation methods, with a third of all students following this model. In the spring 2017 data, students who participated in a manner bound to a location was down to $2 \%$, and even they blended face-to-face teaching with watching on-demand videos. It can be stated with good reason that location is no longer an important consideration in current participation strategies in the degree programme examined in this study. Studying happens outside of classrooms, meaning that the traditional model of blended education is no longer followed.

The portion of students who utilise live and on-demand videos, i.e. students who blend their studies time-based, was roughly a third in the data from 2008-2012, and the role of this method has become more pronounced since then. In the latest data, nearly two fifths of all students blended their studies temporally. The following examines the participations of these students in more detail.

In the 2008-2012 data, there were 27 students who used both live and on-demand videos but never attended face-to-face teaching. In the new data, there were 18 such students. The students were divided into three categories based on to what degree they participated using on-demand videos instead of live videos. Fig. 4 shows that over half of the students who blended their studies based on time in the 20082012 data preferred on-demand videos to live videos. Only one tenth favoured live videos. In the newer data, the 18 students were divided more evenly. The results show that the portion of students who frequently blend live and on-demand videos were largely the same in both sets of data. Results also affirms the previous observation about how live videos have clearly become more significant in the newer data. 


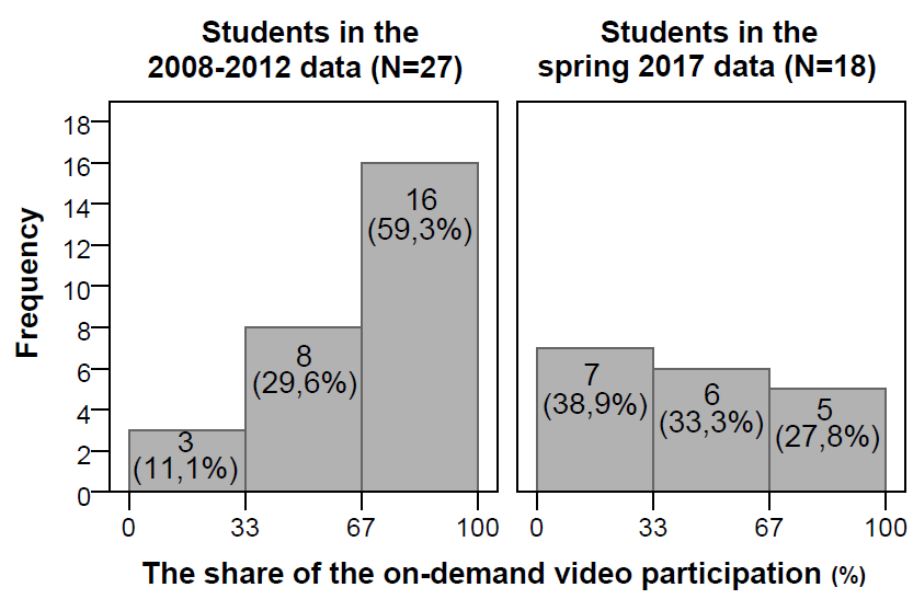

Figure 4. The categorisation of students who blend their studies temporally based on on-demand video viewing.

\section{DISCUSSION}

Students enrolled in the master's degree programme in mathematical information technology at Kokkola University Consortium can freely choose their method of participation between videos and contact teaching. With both live and on-demand videos available, students can make choices regarding both the time and place for studying. The research results clearly showed that participation using videos has become a significant part of studying in the degree programme. The change has been noteworthy, since nowadays nearly all participations in the degree programme are done using videos, and contact teaching has correspondingly lost its place as a participation method. In practice, being bound to a certain location has lost its meaning.

On-demand videos have played an important part for years now, and their role has stayed largely the same from a participation standpoint (Fig. 1). On the other hand, the amount of students relying purely on on-demand videos has increased. Nowadays, more than $2 / 5$ of students participate exclusively by using on-demand videos. The number of students participating by only watching live videos has likewise increased. A few years ago, there were no students who used this method exclusively, while currently one out of five students base their studies on live videos. It is important for the educational organisation to acknowledge that if students favour participation by video more heavily, this should be taken into account in the pedagogics of course implementation.

From a temporal standpoint, synchronous participation interestingly still continues to have a significant role, even though participation in contact teaching has nearly died out. Even though these days nearly half of all students participate by always using either on-demand or live videos, two out of five students blend their studies. Blending is almost exclusively aimed at the temporal aspect.

The results presented in this study can be taken as justification for organising live teaching sessions. However, the results imply that live sessions do not need to take place in a classroom, allowing students to attend face-to-face teaching. This means that technological solutions can be sought to offer highquality education in real-time cost-efficiently, operationally reliably and conventionally by making the education independent of time and place by e.g. using the lecturer's own computer. The possibility of interaction has a key role in synchronous participation. Development resources should in fact be directed into coming up with more functional interaction opportunities alongside live videos.

There are surely many reasons for the changes in participation discussed above. The use of video streaming in everyday life has proliferated during the past few years as a result of the rise in popularity of entertainment services offering these services, for instance. Since videos are a part of students' everyday lives, utilising them in their studies also comes naturally. Faster connection speeds have enabled higher quality video broadcasts and disturbance-free file transfers, making videos more usable. A significant amount of work has been done to develop the video production implemented in the degree programme. This has improved the picture and sound quality of the lecture videos. Implementation of the CiNetCampus Studies environment has no doubt had a major impact in the increased use of videos. The environment improves the meaningfulness of studying using videos by enabling better opportunities to for students to interact and cooperate. The students' awareness of the the possibility of distance learning in the study programme has most likely also played a part in the development of video usage. 
This has probably led to a situation where more students who had already been planning to study remotely are recruited.

\section{CONCLUSIONS}

Blended learning is very common these days. In fact, nearly all teaching is blended to some degree, depending on the definition. According to the most common definition, blending is done in regard to location by utilising various learning environments. In technological environments, studying can take place anywhere. Being bound to a specific location is starting to lose its meaning. On the other hand, education can also be blended temporally, which emphasises various synchronous and asynchronous activities.

Blending can be done by e.g. using lecture videos. By producing videos of contact teaching classes and proving them to students also in real time, education can be blended both temporally and location-wise. Especially synchronous participation using technology poses challenges for interaction. The master's degree programme in mathematical information technology has featured teaching based on lecture videos for a long time. An environment has been built for utilising the videos, and it also supports synchronous participation.

This study shows that participation has changed radically over the past few years. There are many reasons for this. Using on-demand videos to participate independently of time has been a popular method for a long time, and it continues to be the most popular form of participation in the degree programme. Participation that is bound to a location has nearly died out. However, plenty of students continue to participate in real-time, which provides a justification for continuing to organise live teaching sessions. According to the results, physical spaces, i.e classrooms where students come to study, are no longer needed, and education can instead be realised flexibly regardless of location.

This clearly creates pressure to make pedagogical changes. Teaching should not be planned with contact teaching in mind; attention should instead be paid to synchronous distance learning and students who study using recordings at their own pace. The results also imply that development resources should be targeted towards technological solutions that improve the studying opportunities of these students.

\section{ACKNOWLEDGEMENTS}

The research for this paper was financially supported by the European Social Fund, grant no. S20073, without which the present study could not have been completed. The authors wish to thank the Central Finland Centre for Economic Development, Transport and the Environment for their help.

\section{REFERENCES}

[1] A. Norberg, C. D. Dziuban, and P. D. Moskal, "A time-based blended learning model," On the Horizon, vol. 19, no. 3, pp. 207-216, 2011.

[2] C. J. Bonk and C. R. Graham, Handbook of blended learning. Global perspectives, local designs. San Francisco, CA: Pfeiffer Publishing, 2006.

[3] A. G. Picciano and C. D. Dziuban, Blended Learning: Research Perspectives. Needham, MA: Sloan Consortium, 2007.

[4] M. Myllymäki and I. Hakala, "Video-based Blended Learning Practice in Master Studies," 10th IASTED International Conference on Web-based Education, Innsbruck, Austria, 2013.

[5] C. D. Dziuban, J. L. Hartman, F. Juge, P. D. Moskal, and S. Sorg, "Blended learning enters the mainstream," in The Handbook of Blended Learning: Global Perspectives, Local Designs (C.J. Bonk and C.R. Graham, eds.), pp. 195-206, San Francisco, CA: Pfeiffer Publishing, 2006.

[6] C. D. Dziuban, J. L. Hartman, and P. D. Moskal, "Blended learning," EDUCAUSE Center for Applied Research, Research Bulletin, vol. 2004, no. 7, 2004.

[7] A. Littlejohn and C. Pegler, Preparing for Blended E-Learning. Routledge, 2007. 
[8] C. R. Graham, "Blended learning systems: definition, current trends and future directions," in Handbook of blended learning: Global perspectives, local designs (C.J. Bonk and C.R. Graham, eds.), pp. 3-21, San Francisco, CA: Pfeiffer Publishing, 2006.

[9] M. Oliver, and K. Trigwell, "Can 'blended learning' be redeemed?," E-Learning and Digital Media, vol. 2, no. 1, pp. 17-26, 2005.

[10] C. R. Graham, "Emerging practice and research in blended learning," in Handbook of distance education, 3rd ed. (M.G. Moore, ed.), pp. 333-350, New York, NY: Routledge, 2013.

[11] A. G. Picciano, "Blending with purpose: The mutimodal model," Journal of Asynchronous Learning Networks, vol. 13, no. 1, pp. 7-18, 2009.

[12] I. E. Allen and J. Seaman, "Online nation: Five years of growth in online learning," Sloan Consortium report, 2007.

[13] D. R. Garrison and H. Kanuka, "Blended learning: Uncovering its transformative potential in higher education," The Internet and Higher Education, vol. 7, no. 2, pp. 95-105, 2004.

[14] A. G. Picciano, "Blended learning: Implications for growth and access," Journal of Asynchronous Learning Networks, vol. 10, no. 3, pp. 95-102, 2006.

[15] J. Watson, A. Murin, L. Vashaw, B. Gemin, and C. Rapp, "Keeping pace with K-12 online learning: An annual review of policy and practice," Evergreen Education Group report, 2010.

[16] M. T. Power, "The emergence of a blended online learning environment," MERLOT Journal of Online Learning and Teaching, vol. 4, no. 4, pp. 503-14, 2008.

[17] D. Zhang, J. F. Nunamaker, "Powering e-learning in the new millennium: An overview of elearning and enabling technology," Information Systems Frontiers, vol. 5, no. 2, pp. 207-218, 2003.

[18] M. Myllymäki, J. Penttilä, and I. Hakala, "Producing Lecture Videos from Face-to-Face Teaching," International Journal of Information and Education Technology, vol. 4, no. 1, pp. 18$24,2014$. 